\title{
Measuring Joint Hypermobility Using the Hospital Del Mar Criteria - A Reliability Analysis Using Secondary Data Analysis
}

\author{
Domingos Emanuel Bevilacqua ${ }^{1 *}$, Maillard $S^{2}$ and Ferrari J ${ }^{3}$ \\ ${ }^{1}$ Department of Health Sciences, Human Pathology, LARE Federal University of Triangulo Mineiro, Brazil \\ ${ }^{2}$ Specialist Physiotherapist, Great Ormond Street Hospital, UK \\ ${ }^{3}$ School of Health, Sport and Bioscience, University of East London, UK
}

*Corresponding author: Domingos Emanuel Bevilacqua, Department of Health Sciences, Human Pathology, LARE Federal University of Tringulo Mineiro, Brazil.

Received Date: November 22, 2019

Published Date: December 09, 2019

\begin{abstract}
Introduction: While various sets of diagnostic criteria for hypermobility have been published, to date there is no recommended gold-standard, and diagnosis of hypermobility in children and their diagnosis is generally based on clinical judgement.

Objectives: The aims of this study were to test the inter-rater reliability of the Hospital Del Mar criteria, assessing the reliability of the total score as well as individual components of the score.

Methods: Secondary analysis of data was carried out from a retrospective study on a cohort of children under the age of 16 years, related to a joint clinic assessment. Two clinical evaluators examined those subjects using the Hospital Del Mar criteria [1] for diagnosing joint hypermobility $(\mathrm{JH})$. Each evaluator also classified the subject as either hypermobile or normal based on their overall clinical findings. The Kappa statistic was used to calculate the level of agreement between the two evaluators.

Results: Thirty subjects were included in the study ranging in age from 3 to 12 years (mean $=7.02, \pm 2.47$ SD). Of the 30 subjects assessed, 21 $(30 \%)$ were classified as hypermobile. Overall, the prevalence of $\mathrm{JH}$ in this study was higher in boys than in girls.

Conclusion: In this group of children, the Hospital Del Mar criteria appeared to be reliable tool for diagnosing hypermobility. Inter-rater reliability was good to excellent when assessing JH. Specific thresholds for diagnosis need to be set dependant on the age and ethnic group of the population being studied.
\end{abstract}

Keywords: Children; Joint hypermobility; Diagnostic criteria; Iter-rater reliability; Validity; Reproducibility

\section{Introduction}

Joint hypermobility $(\mathrm{JH})$, also known as joint laxity, is a condition where most of an individual's synovial joints present an excessive range of movement (ROM) during passive or active movements, taking in consideration the age, gender and different ethnic group of the subject [2,3]. JH affects around $10 \%$ to $15 \%$ of the world population and is more prevalent in female subjects over male (3:1) [4,5]. Hypermobility decreases as people age [6-8], and it also seems to be associated with race being more frequent in African or Asian individuals when compared with white Caucasian descents $[8,9]$. While JH may be asymptomatic, in some cases it results in musculoskeletal complaints such as arthralgias and joint dislocation [2]. Epidemiological studies suggest that the prevalence of hypermobility depends also on the diagnostic criteria used $[10,11]$. There are several published literatures regarding diagnostic criteria for $\mathrm{JH}$, but to date this condition remains underrecognised and poorly understood, and diagnosis is generally based on clinical judgement [12].

There are many diagnostic criteria established for identifying JH. The first scoring system was developed by Carter and Wilkinson in 1964 [13] and based on evaluation of five items - thumb abduction, elbow extension $>10^{\circ}$, finger extension $>90^{\circ}$, knee extension $>$ $10^{\circ}$, ankle dorsiflexion and foot eversion - scoring a maximum of 
5 points. These criteria were modified by Beighton PH and Horan F [14] in their Beighton and Horan Joint Mobility Index (BHJMI) which included the evaluation of (fifth finger extension, opposition of the thumb, elbow extension, knee extension, and trunk and hip flexion) scoring between zero and nine, where a total of five to nine indicate hypermobility. The latter in turn was amended by Beighton P, et al [15], who developed the Beighton Score to investigate the prevalence of $\mathrm{JH}$ in a rural community in South Africa. In 1983 Rotés J [16] created his own criteria including other items of clinical interest such as shoulder, cervical spine, hip and toe ROM. In 1992 Bulbena A, et al. [1] created the Hospital Del Mar criteria scoring one point/item (overall range zero to ten) including evaluation of apposition of the thumb, metacarpophalangeal, elbow, external shoulder rotation, hip abduction, rotular (patella) hypermobility, ankle and feet hypermobility, metatarsophalangeal, knee hyperflexion and ecchymoses. In 2000 Grahame R, et al. [17] developed the Brighton criteria for JH. These criteria are comprised of two major and/or eight minor criteria based on the Beighton score and four or more out of nine and arthralgia in four or more joints for more than three months. In 2005, Ferrari J, et al. [18]

Table 1: Hospital Del Mar criteria for the assessment of joint hypermobility, (taken from Bulbena A, et al [1]). To score, each side is calculated separately giving a left score and right score. Each yes is given one mark. A total score of ten marks is available.

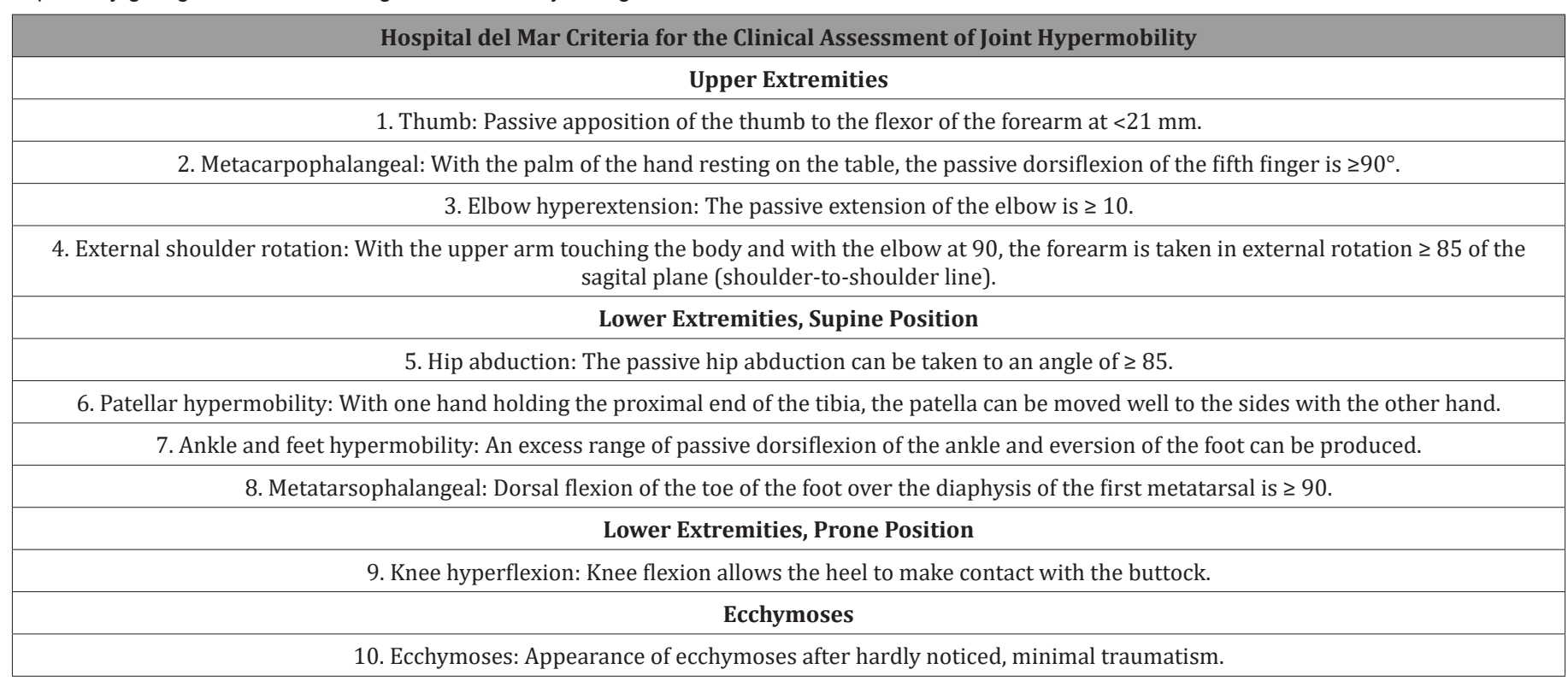

\section{Materials and Methods}

\section{Sample}

Analysis of data was carried out from a retrospective cohort of children assessed in a musculoskeletal clinic. The participants who provided the primary data were children under 16 years, asking to a multidisciplinary specialist, for a joint clinic assessment. Exclusion criteria included children with orthopaedics abnormalities such as hip dislocation, neurological condition, and systemic disease where the pathological conditions that would cause a limit to normal joint movement.

\section{Procedure}

The medical notes were reviewed, and the recordings of the hypermobility joint assessment were extracted. All the subjects included were examined and questioned by two health introduced the Lower Limb Assessment Score (LLAS), specifically designed for assessment of hypermobility in the lower limbs. These tests included movements of the joints in different planes of motion. While each of these criteria have recommendations by authors on how subjects should be scored, no specific thresholds have been determined to enable standardised diagnosis of hypermobile or not. Furthermore, most of these scoring systems are thought to be subjective and very few have been tested for validity and reliability [18]. Hence, to date there is no gold standard criteria for diagnosing $\mathrm{JH}$.

The criteria proposed by Bulbena et al however, have been tested for validity in a previous study [1]. Hence the Hospital del Mar criteria (Table 1) have been shown to be valid tool in the diagnosis of $\mathrm{JH}$. The reliability of these criteria however has not been established Therefore; the main aim of this study is to determine the level of reliability when the criteria are applied by two allied health professionals. Furthermore, a comparison of the classification for hypermobile or not by the two clinical evaluators (using their own clinical experience as a judgment) and the Hospital

Del Mar will be made. 
characteristics of the whole sample. Data from the hypermobility assessment collected from the proforma was transferred onto an Excel spreadsheet. As this study aimed to analyse reliability between two clinical evaluators, the Kappa coefficient was used.
The Kappa value was calculated for each of the criteria, the right and the left side separately. An example of the calculation of Kappa of one category (left thumb) is demonstrated in Table 2. All the other categories were calculated in the same way.

Table 2: Statistical Analysis - The formulae for calculation of Kappa.

\begin{tabular}{|c|c|c|c|c|c|c|c|c|c|}
\hline \multicolumn{10}{|c|}{ Contingency Tables Podiatrist Vs. Physiotherapist } \\
\hline \multirow{2}{*}{\multicolumn{2}{|c|}{$\begin{array}{c}\text { Left Thumb } \\
\text { Yes }\end{array}$}} & \multicolumn{3}{|c|}{ Physiotherapist } & \multirow{2}{*}{\multicolumn{2}{|c|}{$\begin{array}{c}\text { Left Thumb } \\
\text { Yes } \\
\text { No }\end{array}$}} & \multicolumn{3}{|c|}{ Physiotherapist } \\
\hline & & \multirow{2}{*}{$\begin{array}{c}\text { No } \\
\mathrm{a}\end{array}$} & \multirow{2}{*}{$\begin{array}{c}\text { Total } \\
\mathrm{b}\end{array}$} & \multirow[b]{2}{*}{$a+b$} & & & Total & \multirow[b]{2}{*}{$\mathrm{b}$} & \multirow[b]{2}{*}{$a+b$} \\
\hline \multirow{3}{*}{ Podiatrist } & Yes & & & & \multirow{2}{*}{ Podiatrist } & Yes & $((a+c) \times(a+b)) / n$ & & \\
\hline & No & $\mathrm{c}$ & $\mathrm{d}$ & $\mathrm{c}+\mathrm{d}$ & & No & $\mathrm{c}$ & $((b+d) \times(c+d)) / n$ & $\mathrm{c}+\mathrm{d}$ \\
\hline & Total & $\mathrm{a}+\mathrm{c}$ & $b+d$ & $\mathrm{n}$ & & Total & $a+c$ & $b+d$ & $\mathrm{n}$ \\
\hline
\end{tabular}

2a. Observed Frequency 2b. Expected Frequency

*Note: Expected cell frequency (taken from Bowers D [19]) = total of row cell is in $x$ total of column cell is in Overall total frequency.

\section{Results}

\section{Subject demographics}

After applying the exclusion criteria, 30 subjects were included in the study. There was a slightly greater female predominance, 16 females (54\%) and 14 (46\%) males. Age ranged from 3 years to 12 years with an average age of $7.02( \pm 2.47$ standard deviation).

\section{Prevalence of $\mathrm{JH}$}

Of the 30 children assessed, 21 (70\%) were classified as hypermobile, 11 boys (52.3\%) and 10 girls (47.6\%). Nine children (30\%) were classified as a non-hypermobile, three boys $(33.3 \%)$ and six girls (66.6\%). Of the 30 children assessed, two children (one boy and one girl) showed a discrepancy in the clinical diagnosis by the two clinical evaluators, where one ratter classified a child as hypermobile and the other as non-hypermobile. Those children were the subjects 8 and 27. The subject 8 is a 9 years old girl, was classified as non-hypermobile by the podiatrist (HdelM $=3 / 10$ ), but hypermobile by the physiotherapist (HdelM $=5 / 10)$. The subject 27 is an 8 years old boy, scored 4/10 (hypermobile) by the podiatrist, but scored 3/10 (non-hypermobile) by the physiotherapist. Overall, the prevalence of $\mathrm{JH}$ in this study was higher in boys than in girls (Table 3).

Table 3: Level of agreement.

\begin{tabular}{|c|c|}
\hline Kappa & Level of Agreement \\
\hline 0 & Agreement no better than chance \\
\hline$\leq 0.2$ & Poor \\
\hline $0.21-0.4$ & Fair \\
\hline $0.41-0.6$ & Moderate \\
\hline $0.61-0.8$ & Good \\
\hline $0.81-1$ & Excellent \\
\hline 1 & Complete agreement \\
\hline (Bowers D [19]; Daly LE and & \\
\hline Bourke GJ [20]) & \\
\hline
\end{tabular}

\section{Assessment using hospital del mar criteria}

The results from the inter-rater comparison for individual components of the HdelM score using Kappa coefficient are demonstrated in Table 4. Kappa coefficients for the two evaluators were greater than 0.81 (usually considered as an excellent agreement beyond chance) in 2 of the 10 items (thumb and ecchymoses), but bilaterally on thumb and only on the right side for ecchymoses. Three items presented a kappa coefficient value between 0.61 and 0.8 (good agreement), they were shoulder and elbow bilaterally, and ecchymoses on the left side only. Two items presented Kappa value between 0.41 and 0.6 (moderate agreement), they were patella movement and ankle and feet (dorsiflexion / eversion). Two items presented kappa value between 0.21 and 0.4 (considered as a fair agreement), they were metatarsophalangeal on the right side and hip bilaterally. One item (metatarsophalangeal on the left side was below 0.21 (poor agreement). Two items (metacarpophalangeal and knee) could not have their kappa value calculated and were scored zero (agreement no better than chance). In both cases their proportional observed and expected had the same value and so the Kappa could not be calculated.

Table 4: Kappa values for assessment of $\mathrm{JH}$ using the Hospital del Mar criteria by Podiatrist vs. Physiotherapist.

\begin{tabular}{|c|c|c|}
\hline Criteria & \multicolumn{2}{|c|}{ Kappa Values } \\
\hline & Left & Right \\
\hline 1. Thumb & 0.81 & 0.9 \\
\hline 2. Metacarpophalangeal & 0 & 0 \\
\hline 3. Elbow hyperextension & 0.8 & 0.8 \\
\hline 4. External shoulder rotation & 0.71 & 0.71 \\
\hline 5. Hip abduction & 0.29 & 0.29 \\
\hline 6. Patella hypermobility & 0.49 & 0.49 \\
\hline 7. Ankle and feet hypermobility & 0.6 & 0.53 \\
\hline 8. Metatarsophalangeal joint & 0.18 & 0.21 \\
\hline 9. Knee hyperflexion & 0 & 0 \\
\hline 10. Ecchymoses & 0.76 & 0.85 \\
\hline
\end{tabular}

The majority of agreement between medical evaluators occurred on passive apposition of the thumb, passive dorsiflexion of the fifth finger, passive hyperextension of the elbow, external shoulder rotation, knee hyperflexion, and ecchymoses. Most of the disagreement and lower kappa values occurred on passive hip 
abduction, rotular hypermobility, passive dorsiflexion of the ankle and eversion of the foot, and dorsal flexion of the first metatarsal.

Total scores and classification as hypermobile based on clinical experience

Following the assessment of the 30 subjects using the Hospital Del Mar criteria each subject were given a total score on both left and right side of their bodies and they were also classified as hypermobile or not based on clinical experience of the two health professionals who conducted the evaluations. A comparison with the Hospital Del Mar criteria threshold was made to find whether any subject would be missed out when diagnosing hypermobility (Table 5).

Table 5: Classification as hypermobile $(\mathrm{H})$ or not $(\mathrm{N})$.

\begin{tabular}{|c|c|c|c|c|c|c|}
\hline \multirow[b]{2}{*}{ Subjects } & \multirow[b]{2}{*}{ Gender } & \multicolumn{2}{|c|}{ Total Score } & \multicolumn{3}{|c|}{ Classification as Hypermobile or Not } \\
\hline & & Pod & Phys & Pod $^{a}$ & Phys $^{\mathrm{b}}$ & Bulbena $^{c}$ \\
\hline & & $\mathrm{L} / \mathrm{R}$ & $\mathrm{L} / \mathrm{R}$ & & & \\
\hline 1 & M & 9-Sep & $10-$-Oct & $\mathrm{H}$ & $\mathrm{H}$ & $\mathrm{H}$ \\
\hline 2 & $\mathrm{~F}$ & 7-Jul & 5-May & $\mathrm{H}$ & $\mathrm{H}$ & $\mathrm{H}$ \\
\hline 3 & $\mathrm{~F}$ & 9-Sep & 8-Aug & $\mathrm{H}$ & $\mathrm{H}$ & $\mathrm{H}$ \\
\hline 4 & $\mathrm{~F}$ & 8-Aug & 9-Sep & $\mathrm{H}$ & $\mathrm{H}$ & $\mathrm{H}$ \\
\hline 5 & M & 8-Aug & 8-Aug & $\mathrm{H}$ & $\mathrm{H}$ & $\mathrm{H}$ \\
\hline 6 & $\mathrm{M}$ & $10-0 c t$ & $10-0 c t$ & $\mathrm{H}$ & $\mathrm{H}$ & $\mathrm{H}$ \\
\hline 7 & $\mathrm{M}$ & 7-Jul & 7-Jul & $\mathrm{H}$ & $\mathrm{H}$ & $\mathrm{H}$ \\
\hline 8 & $\mathrm{~F}$ & 3-Mar & 5-May & $\mathrm{H}$ & $\mathrm{H}$ & N (Pod) / H (Phys) \\
\hline 9 & M & 8-Aug & 8-Aug & $\mathrm{H}$ & $\mathrm{H}$ & $\mathrm{H}$ \\
\hline 10 & $M$ & 9-Sep & 10 -Oct & $\mathrm{H}$ & $\mathrm{H}$ & $\mathrm{H}$ \\
\hline 11 & $\mathrm{~F}$ & 8-Aug & 9-Sep & $\mathrm{H}$ & $\mathrm{H}$ & $\mathrm{H}$ \\
\hline 12 & $\mathrm{~F}$ & 7-Jun & 7-Jul & $\mathrm{H}$ & $\mathrm{H}$ & $\mathrm{H}$ \\
\hline 13 & $\mathrm{~F}$ & 2 -Feb & 3-Mar & $\mathrm{N}$ & $\mathrm{N}$ & $\mathrm{N}$ \\
\hline 14 & M & 8-Aug & 7-Jul & $\mathrm{H}$ & $\mathrm{H}$ & $\mathrm{H}$ \\
\hline 15 & $\mathrm{~F}$ & 7-Jul & 9-Sep & $\mathrm{H}$ & $\mathrm{H}$ & $\mathrm{H}$ \\
\hline 16 & $\mathrm{M}$ & 7-Jul & 8-Jul & $\mathrm{H}$ & $\mathrm{H}$ & $\mathrm{H}$ \\
\hline 17 & $\mathrm{~F}$ & 9-Oct & $10-0 c t$ & $\mathrm{H}$ & $\mathrm{H}$ & $\mathrm{H}$ \\
\hline 18 & $\mathrm{M}$ & 8-Aug & 9-Sep & $\mathrm{H}$ & $\mathrm{H}$ & $\mathrm{H}$ \\
\hline 19 & M & 8-Aug & 9-Aug & $\mathrm{H}$ & $\mathrm{H}$ & $\mathrm{H}$ \\
\hline 20 & M & 3-Mar & 3-Mar & $\mathrm{N}$ & $\mathrm{N}$ & $\mathrm{N}$ \\
\hline 21 & $\mathrm{~F}$ & $2-\mathrm{Feb}$ & 3-Mar & $\mathrm{N}$ & $\mathrm{N}$ & $\mathrm{N}$ \\
\hline 22 & $\mathrm{~F}$ & 4-Apr & 4-Apr & $\mathrm{N}$ & $\mathrm{N}$ & $\mathrm{N}$ \\
\hline 23 & M & 6-Jun & 9-Sep & $\mathrm{H}$ & $\mathrm{H}$ & $\mathrm{H}$ \\
\hline 24 & $\mathrm{~F}$ & $10-0 c t$ & $10-0 c t$ & $\mathrm{H}$ & $\mathrm{H}$ & $\mathrm{H}$ \\
\hline 25 & $\mathrm{~F}$ & 8-Aug & 7-Jul & $\mathrm{H}$ & $\mathrm{H}$ & $\mathrm{H}$ \\
\hline 26 & $\mathrm{~F}$ & 3-Mar & 3-Mar & $\mathrm{N}$ & $\mathrm{N}$ & $\mathrm{N}$ \\
\hline 27 & $\mathrm{M}$ & 4-Apr & 3-Mar & $\mathrm{N}$ & $\mathrm{N}$ & H (Pod) / N (Phys) \\
\hline 28 & $\mathrm{~F}$ & 4-Apr & 4-Apr & $\mathrm{N}$ & $\mathrm{N}$ & $\mathrm{N}$ \\
\hline 29 & $\mathrm{~F}$ & 2-Feb & 3-Mar & $\mathrm{N}$ & $\mathrm{N}$ & $\mathrm{N}$ \\
\hline 30 & M & 3-Mar & 3-Mar & $\mathrm{N}$ & $\mathrm{N}$ & $\mathrm{N}$ \\
\hline
\end{tabular}

ab Pod and Phys used their own clinical experience to classify the subjects as hyper or not.

'Bulbena's criteria has established threshold cut-off point for males and females, males cut off $\geq 4$ out of 10 positive test and females $\geq 5$ out of 10 to be classified as hypermobile.

Based on the total scores given by the two raters and considering the different cut-off point used in the Hospital Del Mar criteria, two subjects would be missed out on diagnosis of hypermobility. These differences occurred due to discrepancies between the scores given by the two raters to subject 8 and subject 27. The subject 8 was a female who was given a total score of 3 by podiatrist and 5 by physiotherapist. The subject 27 was a male who was given a total score of 4 by podiatrist but a total score of 3 by physiotherapist. Following the Hospital Del Mar criteria threshold the subject 8 could have been classified as non hypermobile if the total score given by podiatrist was taken in consideration, but hypermobile if the total score given by physiotherapist was considered. The subject 27 could have been classified as hypermobile if the total score given by podiatrist was considered, but non hypermobile if the total score 
given by physiotherapist was considered. Despite the difference in the total scores given by the two raters for the above subjects, both professionals classified the subject 8 as hypermobile and the subject 27 as non-hypermobile. These classifications were based on examiners' own clinical experience and on clinical findings.

\section{Discussion}

The results of this study demonstrated some similarities to findings of other studies including similar subject demographics, prevalence of $\mathrm{JH}$ and clinical presentation. This study however demonstrated a higher prevalence of $\mathrm{JH}$ in boys than in girls, in contrast with previous studies which reported higher prevalence of $\mathrm{JH}$ in females [21-25]. The higher prevalence of $\mathrm{JH}$ in males in this study may be occurred due to the small sample size and broad range of age used.

In this study Kappa coefficients for the two raters were greater than 0.81 (usually considered as an excellent agreement beyond chance) in 2 of the 10 items (thumb and ecchymoses), but bilaterally on thumb and only on the right side for ecchymoses. Arguable in this study one subject had a positive score for bruising on one side and negative on the other side reported by the physiotherapist. This one result may have affected Kappa results negatively, because one discrepancy out of 30 can do such difference. The score for ecchymoses should not be necessary for both left and right sides because if an individual is prone to bruise easily it is surely for both sides. Three items presented a kappa coefficient value between 0.61 and 0.8 (good agreement), they were shoulder and elbow bilaterally, and ecchymoses on the left side only. Two items presented Kappa value between 0.41 and 0.6 (moderate agreement), they were patella and ankle and feet. The item patella was expected to have low agreement between the two raters due to the subjective interpretation of the rotular mobility. Two items presented kappa value between 0.21 and 0.4 (considered as a fair agreement), they were metatarsophalangeal on the right side and hip bilaterally. The item hip abduction was expected to have low percentage of agreement between raters because one examiner may mobilise joint tested slightly different with or without hip rotation and the result may be significantly different. One item (metatarsophalangeal on the left side was below 0.21 (poor agreement). Two items (metacarpophalangeal and knee) could not have their kappa value calculated and were scored zero (agreement no better than chance). In both cases their proportional observed and expected had the same value and so the Kappa could not be calculated.

The majority of disagreement and lower kappa values occurred on passive hip abduction, rotular hypermobility, passive dorsiflexion of the ankle and eversion of the foot, and dorsal flexion of the first metatarsal. The disagreement of the above-mentioned items could be due to difference in force applied by the two raters during passive mobility and/or due to lack of training phase in this study for improve the level of agreement between raters for such challenge tests.
In some of the items (elbow, shoulder, hip, and patella) the kappa values were the same in both left and right sides. However, in other items such as thumb, ankle and feet, Metatarsophalangeal, and ecchymoses the kappa values differed significantly between sides. The different kappa values between sides were: left thumb $(\mathrm{k}=0.81)$, right thumb $(\mathrm{k}=0.90)$, left ankle and feet $(\mathrm{k}=0.60)$, right ankle and feet $(\mathrm{k}=0.53)$, left Metatarsophalangeal $(\mathrm{k}=0.18)$, right Metatarsophalangeal $(\mathrm{k}=0.21)$, ecchymoses on the left side $(\mathrm{k}=0.76)$, and ecchymoses on the left side $(\mathrm{k}=0.85)$. It would be advisable to always carry out the assessment of JH using the Hospital Del Mar criteria bilaterally [26-35].

This study investigated the inter-rater reliability of the Hospital del Mar criteria when applied by two allied health professionals to identify hypermobility. A comparison of the classification as hypermobile or not amongst the two raters (using their own clinical experience as a judgment) and the Hospital Del Mar criteria (using different cut-off points for males and females) was made. The findings of this study are in agreement with Bulbena A, et al [1] and conclude that the Hospital Del Mar criteria provide the best ability to distinguish individuals with $\mathrm{JH}$ from those who did not have $\mathrm{JH}$. Through comparison of the three classifications the Hospital Del Mar criteria were shown to have benefits over the already existent scoring systems. If replicated, these findings may give enhanced value to $\mathrm{JH}$ assessment in clinical and general population studies. Specific thresholds for diagnosis need to be set dependant on the age and ethnic group of the population being studied, and this may be investigated in future studies.

\section{Acknowledgement}

None.

\section{Conflict of Interest}

No conflict of interest.

\section{References}

1. Bulbena A, Duro JC, Porta M, Faus S, Vallescar R, et al. (1992) Clinical assessment of hypermobility of joints: assembly criteria. J Rheumatol 19(1): 115-122.

2. Kirk JH, Ansell B, Bywaters EG (1967) The hypermobility syndrome: musculoskeletal complaints associated with generalized joint hypermobility. Ann Rheum Dis 26(5): 419-425.

3. Grahame R (2003) Hypermobility syndrome: Recognition and management for physiotherapist. In: Keer R, Grahame R (eds), Hypermobility and hypermobility syndrome $1^{\text {st }}(\mathrm{edn})$, Edinburgh Butterworth Heinemann, pp. 1-14.

4. Beighton PH, Grahame R, Bird HA (1999) Hypermobility of joints $3^{\text {rd }}$ (edn). Springer, UK.

5. Bulbena A, Gago J, Pailhez G, Sperry L, Fullana MA, et al. (2011) Joint hypermobility syndrome is a risk factor trait for anxiety disorders: a 15 year follow-up cohort study. Gen Hosp Psychistry; 33(4): 363-370.

6. Bridges AJ, Smith E, Reid J (1992) Joint hypermobility in adults referred to rheumatology clinics. Ann Rheum Dis 51(6): 793-796.

7. Larsson LG, Baum J, Mudholkar GS, Skivastava DK (1993) Hypermobility: Prevalence and features in a Swedish population. Br J Rheumatol 32(2): 116-119. 
8. Russek L (1999) Hypermobility syndrome. Phys Ther 79: 591-97.

9. Cherpel A Marks R (1999) The Benign joint hypermobility syndrome. N Z J Physiother 27: 9-22.

10. Al Rawi ZS, Al Aszawi AJ, Al Chalabi T (1985) Joint mobility among university students in Iraq. Br J Rheumatol 24(4): 326-331.

11. Birrel FN, Adebajo A, Hazleman BL, Silman AJ (1994) High prevalence of joint laxity in West Africans. Br J Rheumatol 33(1): 56-59.

12. Keer R, Grahame R (2003) Hypermobility syndrome: Recognition and management for physiotherapist. In: Keer R, Grahame R (eds). Butterworth Heinemann.

13. Carter C, Wilkinson J (1964) Persistent joint laxity and congenital dislocation of the hip. J Bone Joint Surg Br 46: 40-45.

14. Beighton PH, Horan F (1969) Orthopaedics aspects of the Ehlers-Danlos syndrome. J Bone Joint Surg Br 51(3): 444-453.

15. Beighton P, Solomon L, Soskolne CL (1973) Articular mobility in African population. Ann Rheum Dis 32(5): 413-418.

16. Rotés J (1983) Reumatologia Clinica. Barcelona: Espaxs.

17. Grahame R, Bird HA, Child A (2000) The revised (Brighton 1998) criteria for the diagnosis of benign joint hypermobility syndrome (BJHS). Rheumatol 27(7): 1777-1779.

18. Ferrari J, Parslow C, Lim E, Hayward A (2005) Joint hypermobility: The use of a new assessment tool to measure lower limb hypermobility. Clin Exp Rheumatol 23(3): 413-420.

19. Bowers D (2008) Medical Statistics from Scratch $2^{\text {nd }}(e d n)$. West Sussex: John Wiley and Sons, Limited.

20. Daly LE, Bourke GJ (2000) Interpretation and Uses of Medical Statistics $5^{\text {th }}(\mathrm{edn})$. Oxford: Blackwell Science.

21. Biro F, Gewanter HL, Baum J (1983) The hypermobility syndrome Pediatr 72(5): 701-706.

22. Klemp P, John ES, Sedick I (1984) A hypermobility study in ballet dancers. J Rheumatol 11(5): 692-696.
23. Larsson LG, Baum J, Mudholkar GS (1987) Hypermobility: features and differential incidence between the sexes. Arthritis Rheum 30(12): 14261430.

24. Jansson A, Saartok T, Werner S, Renström P (2004) General joint laxity in 1845 Swedish school children of different ages: age- and gender-specific distributions. Acta Paediatr 93(9): 1202-1206.

25. Bird HA (2004) Joint hypermobility. Musculoskelet Care 5(1): 4-19.

26. Grahame R (1999) Joint hypermobility and genetic collagen disorders: are they related? Arch Dis Child 80(2): 181-191.

27. Child AH (1986) Hypermobility syndrome: inherited disorder of collagen synthesis. J Rheumatol 13(2): 239-243.

28. Beighton PH, Graham R, Bird HA (1989) Genetic aspects of the hypermobility syndrome. In: Beighton PH, Graham R, Bird HA (eds), Hypermobility of joints $2^{\text {nd }}(\mathrm{edn})$, Springer, Germany

29. Bulbena A, Duro JC, Porta M, Vallejo J (1988) Joint hypermobility syndrome and anxiety disorders. Lancet 2(8612): 694.

30. Beighton PH, Graham R, Bird HA (1989) Clinical features of hypermobility syndrome. In: Beighton PH, Graham R, Bird HA (eds), Hypermobility of joints $2^{\text {nd }}(\mathrm{edn})$, Springer, Germany.

31. Bravo JF, Wolff C (2006) Clinical study of hereditary disorders of connective tissues in a Chilean population. Arthritis Rheum 54(2): 515523.

32. Tofts LJ, Elliot EJ, Munns C, Pacey V, Sillence DO (2009) The differential of children with joint hypermobility: a review of the literature. Pediatr Rheumatol Online J 7:1.

33. Grahame R (1990) The hypermobility syndrome. Ann Rheum Dis 49: 199-200.

34. Gedalia A, Person DA, Brewer EJ, Giannini EH (1985) Joint hypermobility in juvenile episodic arthritis/arthralgia. J Pediatr 107(6): 873-876.

35. Viera AJ, Garret JM (2005) Understanding Interobserver Agreement: The Kappa Statistic. Fam Med 37(5): 360-363. 